\title{
Intestinal mantle cell lymphoma observed by double-balloon endoscopy with Fuji Intelligent Chromo Endoscopy
}
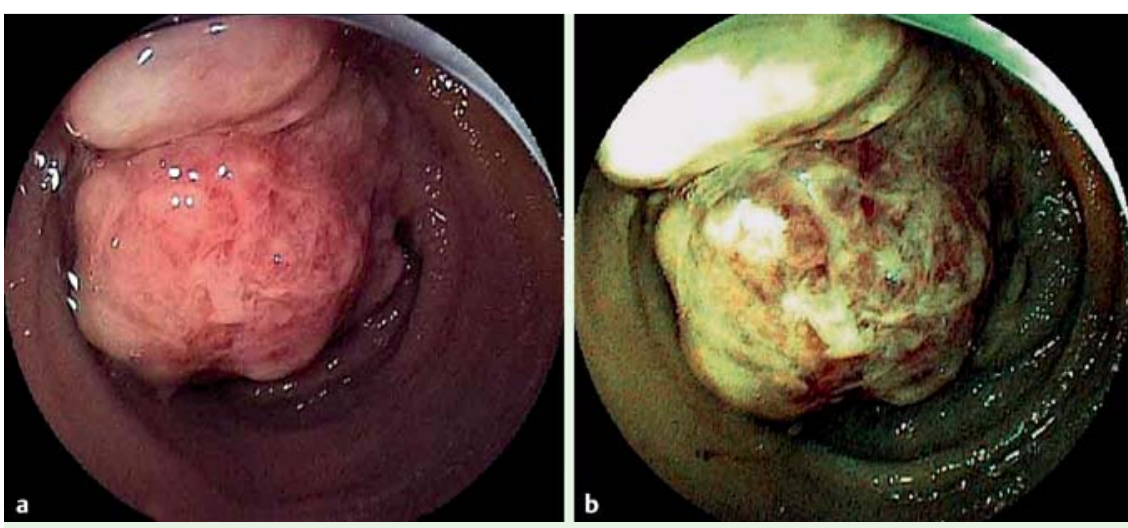

Fig. 1 a Double-balloon endoscopy showed a reddish irregular elevated mass lesion with giant folds in the distal ileum. b Fuji Intelligent Chromo Endoscopy (FICE) highlighted superficial vessels.
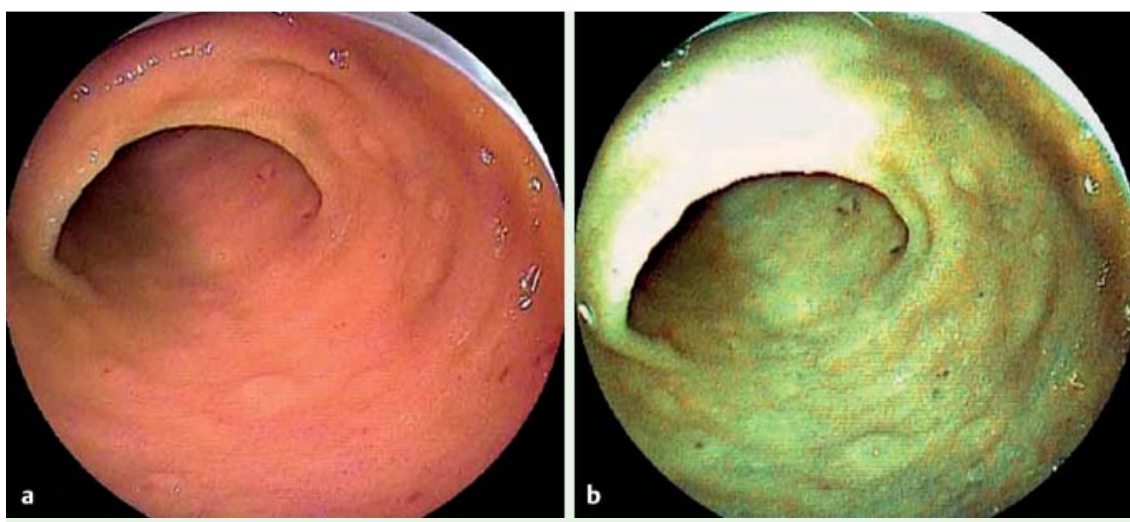

Fig. 2 a Multiple small polypoid lesions were spread in the distal ileum. b Fuji Intelligent Chromo Endoscopy (FICE) identifed them clearly as small whitish nodules.
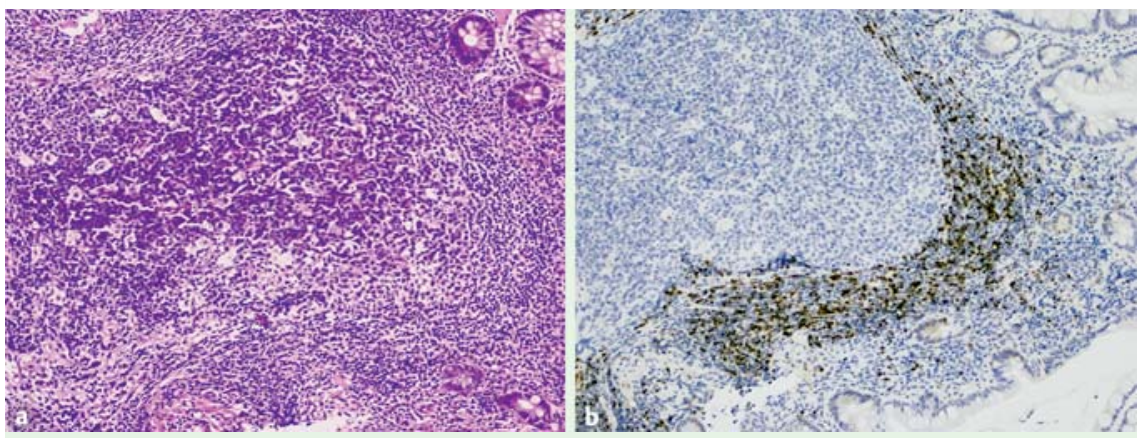

Fig. 3 a Endoscopic biopsy specimens taken from the mass lesion and small polypoid lesions showed follicular structures within the thick mantle layer under the mucosa, consisting of medium-sized abnormal lymphoid cells with dense nuclei. b Immunohistochemical analysis revealed that the mediumsized abnormal lymphoid cells were positive for cyclin D1.
Mantle cell lymphoma rarely occurs in the gastrointestinal tract, although other Bcell-derived non-Hodgkin lymphoma often occurs there. According to previous reports, gastrointestinal spread of mantle cell lymphoma frequently involves the colorectum and stomach; reports of small-intestinal involvement are rare. Consistent with preceding reports [1-3], the endoscopic appearance of colorectal and small-intestinal spread of mantle cell lymphoma shows multiple lymphomatous polyposis in the lower ileum and colorectum. Earlier reports have described cases of gastrointestinal mantle cell lymphoma using advanced endoscopic imaging technologies [1-3], but observation of mantle cell lymphoma of the small intestine using double-balloon endoscopy with Fuji Intelligent Chromo Endoscopy (FICE) has not been reported to date. We report a rare case of intestinal mantle cell lymphoma diagnosed by capsule endoscopy and double-balloon endoscopy with FICE, providing a new mode of endoscopic imaging of this type of gastrointestinal lymphoma.

A 66-year-old man was admitted to our hospital for anemia and tarry stool. Upper gastrointestinal endoscopy and total colonoscopy showed no remarkable changes. Capsule endoscopy showed elevated lesions in the distal ileum, and double-balloon endoscopy was undertaken for further examination. Double-balloon endoscopy showed a reddish irregular elevated mass lesion with giant folds in the distal ileum and FICE highlighted superficial vessels ( $\bullet$ Fig. 1).

Multiple small polypoid lesions were present in the distal ileum and FICE could identify them clearly as small whitish nodules ( $\bullet$ Fig. 2).

Endoscopic biopsy specimens taken from the mass lesion and small polypoid lesions showed follicular structures within the thick mantle layer under the mucosa, consisting of medium-sized abnormal lymphoid cells with dense nuclei ( $\bullet$ Fig. $3 a$ ). Immunohistochemical analysis revealed that the medium-sized abnormal lymphoid cells were positive for cyclin D1 (ه Fig. 3b), CD5, CD20, Bcl-1 and Bcl-2, but negative for CD3 and CD10. Based on 
histopathological and immunophenotypic findings, a diagnosis of intestinal mantle cell lymphoma was made.

Endoscopy_UCTN_Code_CCL_1AC_2AC

Competing interests: None

D. Norimura ${ }^{1}$, H. Isomoto ${ }^{1}$, D. Niino ${ }^{2}$, Y. Akazawa ${ }^{1}$, N. Yamaguchi ${ }^{1}$, K. Ohnita ${ }^{1}$, S. Shikuwa ${ }^{1}$, F. Takeshima ${ }^{1}$, K. Nakao ${ }^{1}$

1 Department of Gastroenterology and Hepatology, Nagasaki University Hospital, Nagasaki, Japan

2 Department of Pathology, Kurume University Hospital, Kurume, Japan

\section{References}

1 Hotta K, Oyama T, Kitamura Y et al. Mantle cell lymphoma presenting as multiple lymphomatous polyposis spreading widely to the small intestine. Endoscopy 2007; 39 (Suppl 1): E347-E348

2 Penyige J, Farczadi E, Boer $K$ et al. A rare intestinal malignancy: mantle cell lymphoma. Endoscopy 2007; 39: E60

3 Yumori A, Okubo H, Takahashi H et al. Gastrointestinal: mantle cell lymphoma diagnosed by balloon enteroscopy. J Gastroenterol Hepatol 2008; 23: 1623
Bibliography

DOI $10.1055 / \mathrm{s}-0030-1255986$

Endoscopy 2011; 43: E26-E27

(c) Georg Thieme Verlag KG Stuttgart · New York . ISSN 0013-726X

Corresponding author

D. Norimura, MD

Nagasaki University Hospital

1-7-1 Sakamoto

Nagasaki 852-8501

Japan

Fax: +81-95-8197482

norir333081@yahoo.co.jp 